\title{
Surface Contamination in Skin and Room during Hospitalization of Thyroid Cancer Patient Receiving Radioiodine Ablation
}

\author{
Hamizah $\mathrm{NMZ}^{1}$, Juliana $\mathrm{MR}^{1}$, Waidi $\mathrm{AI}^{2}$, Ismalina $\mathrm{SNI}^{3}$, Ahmad $\mathrm{Z}^{2}$ \\ ${ }^{1}$ Faculty of Medicine and Health Sciences, University Sultan Zainal Abidin, Malaysia \\ ${ }^{2}$ School of Health Sciences, University Science Malaysia, Malaysia \\ ${ }^{3}$ School of Medical Sciences, Universiti Science Malaysia, Malaysia
}

\begin{abstract}
The large amount of iodine-131 $\left({ }^{131}\right.$ I) activity excreted by the patient via perspiration, saliva, breath and urine during hospitalization may develop radiation contamination hazard. The aim of this study was to measure the level of contamination activity from skin and room surfaces throughout radioiodine ablation patient's hospitalization and to determine the correlation between the administrated dose and level of contamination activity from skin and room surfaces. The removable activity was measured from nine patients treated with radioactive ${ }^{131} \mathrm{I}$ with doses ranged from 3.0 to $5.5 \mathrm{GBq}(80-200 \mathrm{mCi})$. The measurement was made at patient's skin and room surfaces in the three-time interval of 4, 10 and 24 hours. The results showed that the removable activity for skin and room surfaces exceeds the regulation level for most of the time post ${ }^{13 I} I$ administration throughout patient's hospitalizations. There was no significant correlation between levels of surface contamination and treatment dose received by the patient. The radiation safety precautions must be considered in order to minimize radiation exposure to the family, personnel and community either during hospitalization or after discharge.
\end{abstract}

Keywords: Iodine-131 $\left({ }^{131} I\right)$, Radioiodine ablation, Radiation contamination, Radiation exposure, Surface contamination.

\section{INTRODUCTION}

Radioiodine ablation is a treatment of choice for thyroid cancer patient following total thyroidectomy in which radioactive source is used. The goal of ablation is to destroy these remnants in a belief that such therapy will be followed by a reduction in recurrences and mortality from the carcinoma [1]. High dose radioactive Iodine-131 $\left({ }^{131} \mathrm{I}\right)$ is administered in a large amount of activities between 2.75 to $7.4 \mathrm{GBq}(75-200$ $\mathrm{mCi}$ ) [2]. $87 \%$ of patients with residual thyroid bed tissue can achieve total ablation with $3700-7400 \mathrm{MBq}$ (100$200 \mathrm{mCi}$ ) and no significant increment was observed by giving higher doses [3]. The administration of ${ }^{131} \mathrm{I}$ is normally by the oral route, intravenous injection, or installation of colloidal suspensions into closed body cavities [4].

${ }^{131} \mathrm{I}$ emits both negative beta particles with maximum energy approximately $807 \mathrm{keV}$ which delivers the major radiation dose to the remnant thyroid tissue and a prominent $364-\mathrm{keV}$ gamma photon which poses a potential radiation hazard to others outside the patient's room [5]. The patients become a risk of radiation exposure and potential radiation hazards to the other individuals after radioiodine therapy administration. Most patients who receive high dose of ${ }^{131} \mathrm{I}$ therapy are isolated in a private room from two to three days to allow the radiation exposure rates drop to the accepted levels for radiation protection purposes [6,7]. The isolation procedures are commanded to minimize the transfer of contamination to the hospital personnel or visitors. Upon released of the patient, it is required to properly instruct them in order to minimize the radiation contamination and exposure to the person living with or coming in contact with the patient [8].

Radioiodine is secreted in body fluids such as sweat and saliva and excreted into urine and faeces [9]. The amount of residual thyroid tissue in thyroid cancer patient determines the radioiodine retention and clearance rate. Patients undergoing second treatment will have less thyroid tissue compared to those undergoing initial treatment, thus they have higher clearance rate. In cancer patients, because of the lack of thyroid tissue, most of the administered activity will appear in the urine. The fraction is largely be determined by the amount of remnant and metastatic thyroid tissue. In most cases, 50-60\% of the administered activity is excreted in the first 24 hours, and around $85 \%$ over a stay of $4-5$ days. This represents a significant potential for radioactive contamination [3].

Due to the large amount of activity excreted by the patient during hospitalization, contamination hazard may arise from ${ }^{131} \mathrm{I}$ via urine, saliva and perspiration and potential vomitus. The excretion would results in the possibility of contamination of the patient's environment and of inadvertent ingestion by other persons [4]. Radioactive contamination is described as the contamination of any material, surface or environment or of any person, including both external skin contamination and internal contamination irrespective of the method of intake, by any radioactive material, nuclear material or prescribed substance [10]. The contamination risk to the 
relatives of patients and community members through external rays and body fluids from patients in the treatment of radioactive iodine is an important issue that needs to be considered [11]. Precautions should be taken to limit the radiation exposure of the nuclear medicine physician, nursing personnel, the patient's family, and members of the public with whom a treated patient may come in contact. These precautions vary among countries, but recommendations are usually based on measurement of ${ }^{131} \mathrm{I}$ retention or instantaneous dose rates [9].

There are very few reports regarding the ${ }^{131}$ I contamination during the radioiodine therapy for thyroid cancer patients. One of the study found that the removable activity from the skin and room surfaces exceeded acceptable levels of removable contamination for restricted areas during hospitalization and at a time of discharge [8]. The European Union (EU) states that treatment of thyroid cancer using radioiodine ${ }^{131} \mathrm{I}$ should only be performed on inpatients and the patient must be hospitalized for at least 48 hours [4]. The United State Nuclear Regulatory Commission (NRC) guide 8.39 describes several options for patient release after radioiodine therapy: the administered activity of the patient less than $1.2 \mathrm{GBq}$, dose rate less than $18.1 \times 10^{-7} \mathrm{Ckg}^{-}$ ${ }^{1} / \mathrm{hr}$ or $7 \mathrm{mR} / \mathrm{h}$ at 1 meter [12]. The purpose of this study was to measure the level of contamination activity released by patients treated with radioiodine therapy during hospitalization and to determine the correlation between the administrated dose and level of contamination activity from skin and room surfaces.

\section{MATERIALS AND METHODS}

\subsection{Patients and Treatment}

Nine patients received ${ }^{131} \mathrm{I}$ ablation following thyroidectomy for follicular and papillary thyroid cancer has been chosen as subjects for this study. The patient population consisted of 3 males and 6 females. The age ranged from 16 to 73 years old with a mean age of 50.56 years. The number of sample size is small due to lack of thyroid ablation cases in this hospital. Based on the previous study conducted in Wisconsin United State, only eight patients with thyroid cancer treated with activities ranging from 3.7 to $14.8 \mathrm{GBq}$ [8]. Patients were administered a therapeutic amount of ${ }^{131} \mathrm{I}$ - labelled sodium iodide orally which in activity from 3.0 to $5.5 \mathrm{GBq}$ ( 80 to $150 \mathrm{mCi}$ ). Patients were hospitalized and isolated for about two days until the administered activity was no greater than $1.2 \mathrm{GBq}$ [11]. Each patient was informed about the procedure and gave their consent.

The removable surface contamination levels were measured from the room surfaces, the toilet bowl surface and the skin surface. The samples of removable contamination were obtained for three times during patient's hospitalization, which were at 4,10 and 24 hours. Alcohol swabs were used to get the samples from patient's skins and room surfaces. All wipe samples were taken from an area about $2 \mathrm{~cm} \times 5 \mathrm{~cm}$. The skin wipe samples were taken from the forehead, neck, chest, forearm and palm. While wipe samples for room surfaces contamination were obtained from tray stand, faucet, door handle and surface of toilet bowl. All samples were measured using thyroid uptake probe that was calibrated by using residual syringe with $1.45 \mathrm{mCi}$ of ${ }^{131} \mathrm{I}$. The energy spectrum of the $364 \mathrm{keV}$ peak of ${ }^{131} \mathrm{I}$ selected at $15 \%$ of the windows. The sensitivity test was performed to test the constancy of instrument and setting. The calibration result is $45.9 \mathrm{kcps} / \mu \mathrm{Ci}$. Known activity of ${ }^{131} \mathrm{I}$ source was counted to convert counts to units of Becquerel per centimetre square. The background was counted to ensure the instrument stability.

\subsection{Statistical Analysis}

Data were analyzed to find the correlation between ${ }^{131} \mathrm{I}$ treatment dose and the removable activity detected at 4, 10 and 24 hours after oral administration. Nonparametric or distribution-free statistical test was chosen and correlation between the continuous variables was analyzed with the Spearman's rank order correlation. All data analysis was conducted using Statistical Package for Social Sciences, Predictive Analysis Software version 18 (SPSS PASW 18).

\section{III.}

\section{RESULTS}

Fig. $1-5$ showed the results of removable ${ }^{131}$ I contamination measurements from skin surfaces post radioiodine administration at different time interval 4, 10 and 24 hours. The removable surface activity from room surfaces at 4, 10 and 24 hours has been demonstrated in Fig. 6 . These graphs displayed are subdivided according to the dose received by the thyroid cancer patients. There were six patients who received $3.7 \mathrm{GBq}$, and one patient for each 3.0 GBq, 4.4 GBq and 5.5 GBq. Measurement of the activities of all skin wipe samples range from less than $20 \mathrm{~Bq} / \mathrm{cm}^{2}$ to over $400 \mathrm{~Bq} / \mathrm{cm}^{2}$. Some of the surface showed no removable activity, while most of them exceed the limit as stated in US NRC Regulatory guide 8.23 [12]. Wipe samples taken from the five skin surfaces and four room surfaces showed a different time activity pattern. The highest removable contamination for skin surfaces detected 4 hours post administration at chest region which is $427 \mathrm{~Bq} / \mathrm{cm}^{2}$ for patient treated with $3.0 \mathrm{GBq}$ of ${ }^{131} \mathrm{I}$ (Fig. 3). The mean activity for other skin surfaces was eventually equal for all cases. 
In Fig. 6, the removable activity from room surfaces ranged from less than $30 \mathrm{~Bq} / \mathrm{cm}^{2}$ to over 7.3 $\mathrm{kBq} / \mathrm{cm}^{2}$. Removable activity of room surfaces showed the greatest contamination which at toilet bowl surfaces for the same subject who received $3.0 \mathrm{GBq}$ of ${ }^{131} \mathrm{I}$. According to the graphs, the highly potential contaminated room surfaces are the faucet and toilet bowl surfaces. This may result from frequent visit to the toilet for all subjects. The removable activity was high for all wipe samples at 4 hours post ${ }^{131} \mathrm{I}$ administration with exclusion for subject treated with $3.0 \mathrm{GBq}$. Upon 24 hours post therapy, the results showed that the removable activity for some subjects was decreasing while for some of them the activity was increasing. Subject treated with $3.0 \mathrm{GBq}$ shows reduction in contamination activity for most skin and room surfaces except for toilet bowl surface.

The removable contamination for all cases either for skin or room surfaces were inconsistent. Generally it is assumed that the removable contamination is proportional to the administered dose received by the patient. But the study showed there was no significant correlation between radioiodine contamination and administrated dose.

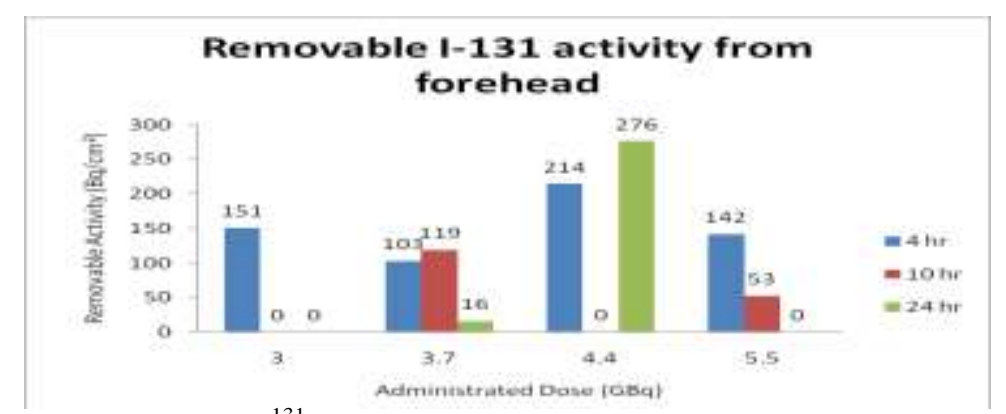

Figure 1. The removable activity of ${ }^{131}$ I from forehead at different time interval for different administrated doses.

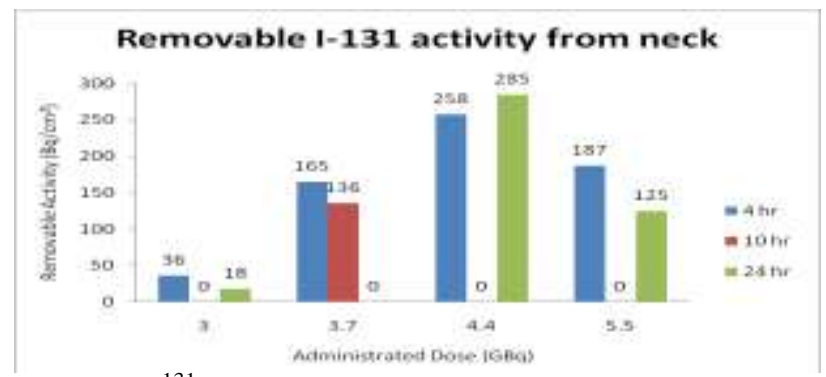

Figure 2. The removable activity of ${ }^{131}$ I from neck at different time interval for different administrated doses.

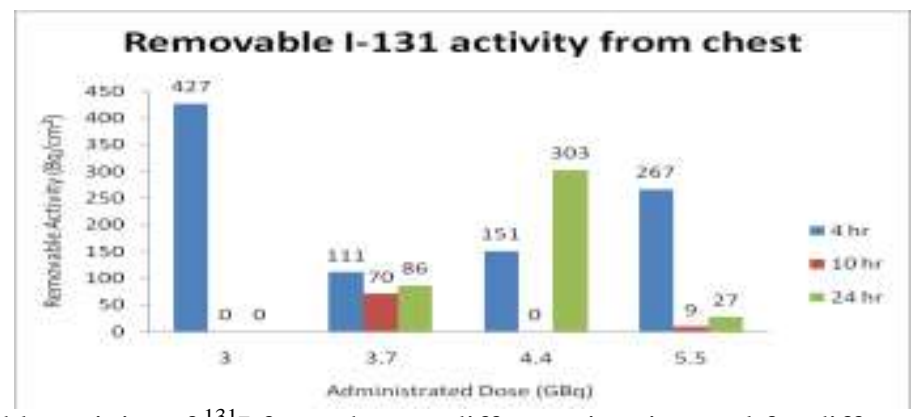

Figure 3. The removable activity of ${ }^{131}$ I from chest at different time interval for different administrated doses.

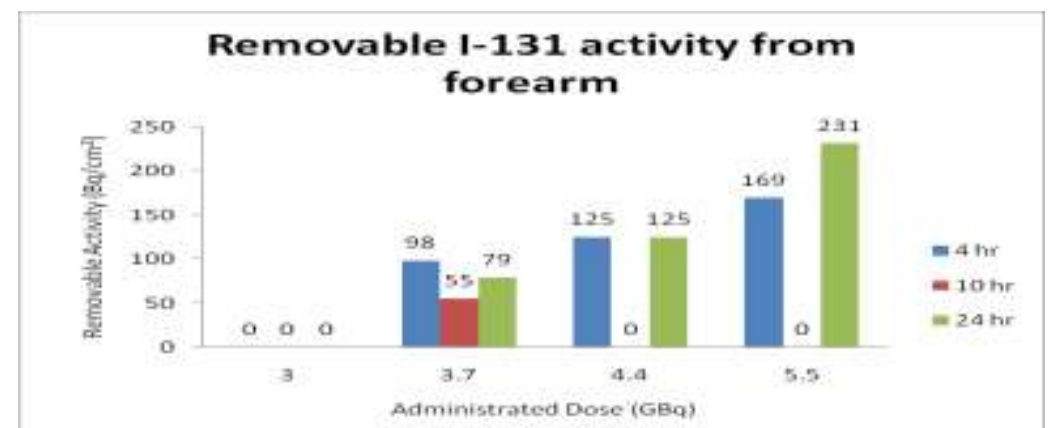

Figure 4. The removable activity of ${ }^{131} \mathrm{I}$ from forearm at different time interval for different administrated doses. 


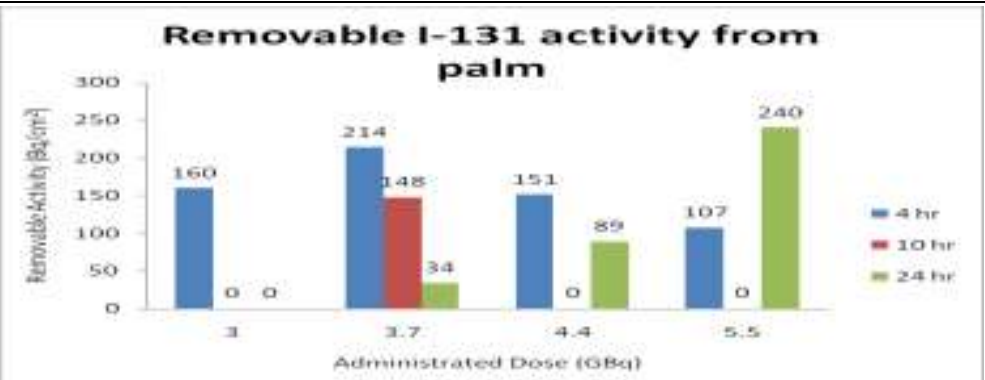

Figure 5. The removable activity of ${ }^{131}$ I from palm at different time interval for different administrated doses.

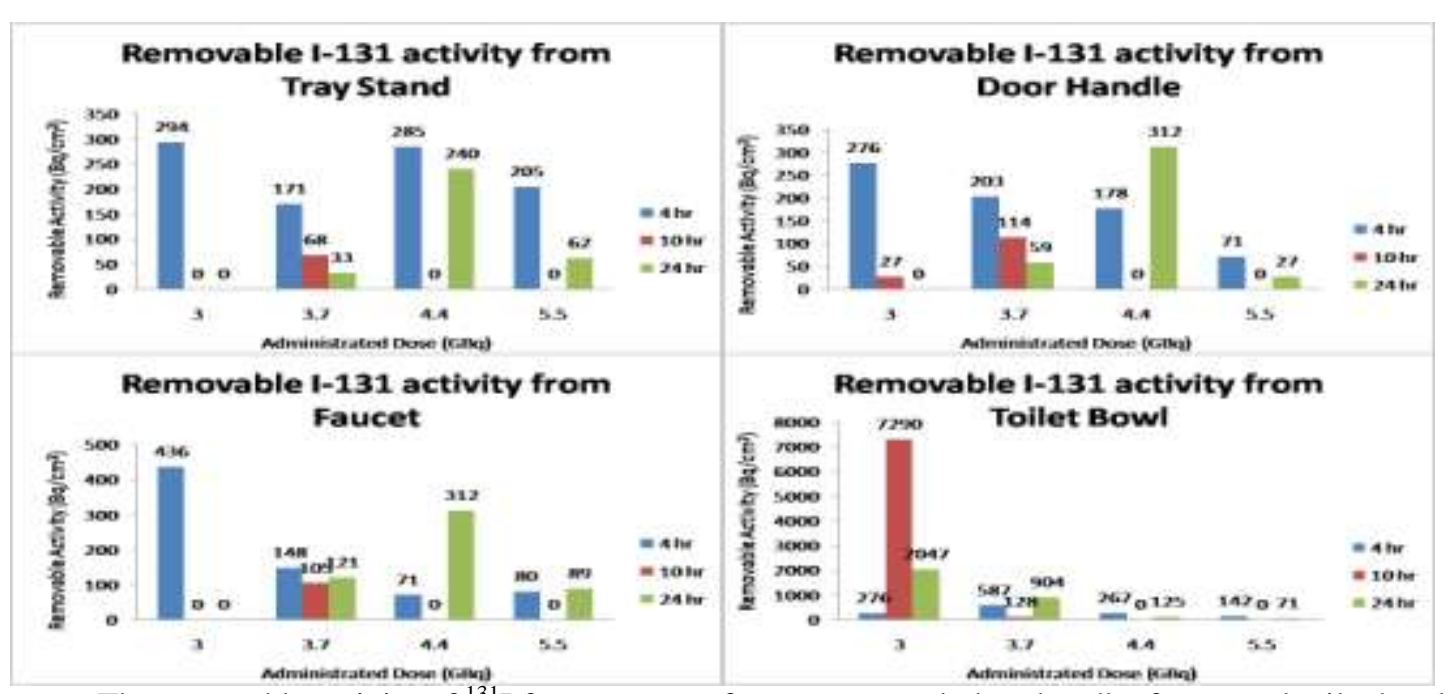

Figure 6. The removable activity of ${ }^{131}$ I from room surfaces; tray stand, door handle, faucet and toilet bowl at different time interval for different administrated doses.

Table 1 demonstrated correlation between administered dose and removable surface activity per centimetre square at different time interval 4,10 and 24 hours post ${ }^{131} \mathrm{I}$ administration for skin surfaces. The results showed greater removable activity variability at different time interval 4,10 and 24 hours post ${ }^{131} \mathrm{I}$ administration (Table 1 and Table 2). At 4 hour post administration only forehead, neck and forearm showed no significant positive correlation between treatment dose and removable activity for the skin surface. Neck, forearm and palm showed no significant negative correlation between treatment dose and removable activity at 10 hour post ablation. The forehead surface however showed no significant relationship between treatment dose and removable activity $(r=0.00, p=1.000)$. At 24 hour post administration the entire skin surface involved also showed no significant positive correlation between treatment dose and removable activity except palm.

Table 1: Correlation between ${ }^{131}$ I treatment dose and removable activity at 4,10 and 24 hours post ${ }^{131} \mathrm{I}$ administration for different skin surfaces.

\begin{tabular}{cccc}
\hline Skin Surfaces & $\begin{array}{c}\text { Time Interval } \\
\text { (hours) }\end{array}$ & Correlation Coefficient (r) & $\boldsymbol{p}$-value \\
Forehead & 4 & 0.16 & 0.679 \\
& 10 & 0.00 & 1.000 \\
Neck & 24 & 0.34 & 0.411 \\
& 4 & 0.59 & 0.095 \\
& 10 & -0.16 & 0.683 \\
Chest & 24 & 0.48 & 0.188 \\
\hline \multirow{3}{*}{ Forearm } & 4 & -0.06 & 0.888 \\
& 10 & 0.21 & 0.584 \\
& 24 & 0.47 & 0.20 \\
\hline \multirow{2}{*}{ Palm } & 4 & 0.42 & 0.257 \\
& 10 & -0.16 & 0.683 \\
& 24 & 0.61 & 0.084 \\
\hline
\end{tabular}


Table 2 represented the correlation between administered dose and removable surface activity per centimetre square at different time interval; 4, 10 and hours post ${ }^{131} \mathrm{I}$ administration for room surfaces. According to table 2, entire room surfaces involved in this study showed negative correlation but not significant between treatment dose and removable activity at 4 hour post ablation. The situation was similar at 10 hour post ablation except for toilet bowl surface which showing significantly negative correlation. At 24 hours post ablation only toilet bowl surface showed no significant negative correlation compared to other surfaces $(r=-$ $0.34, p$-value $=0.364$ )

Table 2: Correlation between ${ }^{131}$ I treatment dose and removable activity at 4,10 and 24 hours post ${ }^{131}$ I administration for different room surfaces.

\begin{tabular}{cccc}
\hline $\begin{array}{c}\text { Room } \\
\text { Surfaces }\end{array}$ & Time Interval (hours) & Correlation Coefficient (r) & $p$-value \\
& 4 & & \\
Tray stand & 10 & -0.07 & 0.859 \\
& 24 & -0.20 & 0.615 \\
\hline \multirow{2}{*}{ Door } & 4 & 0.66 & 0.055 \\
handle & 10 & -0.21 & 0.597 \\
& 24 & -0.42 & 0.257 \\
Faucet & 4 & 0.54 & 0.132 \\
& 10 & -0.46 & 0.210 \\
\hline \multirow{2}{*}{ Toilet bowl } & 24 & -0.20 & 0.615 \\
& 4 & 0.53 & 0.143 \\
\hline
\end{tabular}

Based on Table 1 and Table 2, no significant correlation was found between the dose administered and removable activity for most of skin and room surfaces. But however, removable activity for palm at 24 hours post ablation, showed significantly positive correlation with the treatment dose $(r=0.70, p$-value $=0.037)$. There was also significantly good negative correlation between treatment dose and removable activity at 10 hours post ${ }^{131} \mathrm{I}$ administration for toilet bowl surface $(r=-0.70, p$-value $=0.035)$.

\section{DISCUSSION}

Referring to US NRC Regulatory Guide 8.23 [13], the level of contamination in restricted area at which clean up is recommended is $2200 \mathrm{dpm} / 100 \mathrm{~cm}^{2}$ or $0.36 \mathrm{~Bq} / \mathrm{cm}^{2}$. In this study, the removable activity for skin and room surfaces exceeded the regulation level for most of the time post ${ }^{131} \mathrm{I}$ administration throughout patient's hospitalizations. The high contamination level probably indicates the amount of contact each surface has with the patient's hands and saliva ${ }^{[8]}$. In this study, there was no significant correlation between the treatment doses and activity levels of contamination. The patient who received $80 \mathrm{mCi}{ }^{131} \mathrm{I}$ may have high surface contamination compared to patient treated with $200 \mathrm{mCi}$. The contamination for the patients received same amount of treatment doses also not necessarily same. It may vary from patient to patient.

The contamination from the radioiodine patient is not dependent on the amount of the radioactive ${ }^{131} \mathrm{I}$ they had received, but it strongly depends on the patients behaviour, biologic processes and their compliance with the safety instruction given by the radiation safety officer and other medical staff. For bound radioiodine (fraction taken up by thyroid and other tissues) the biological half-life will vary from patient to patient, depending on the amount of thyroid tissue, their thyroidal hormonal status, and the presence of any metastatic deposits, and is very much longer compared to the physical half-life [3]. The total amount of radioactive iodine reduces to half of its original value at a rate depends on the state of disease which is between one day for total ablation of thyroid cancer tissue [11].

The uptake of radioactive ${ }^{131} \mathrm{I}$ in the thyroid cancer often depends on the condition of the thyroid, whether it has been removed or not, and it varies from patient to patient for the same amount of radionuclide. The biologic processes of the patients also affect the clearance of radionuclide. Patients received ${ }^{131}$ I therapy do not retain radioactivity for the physical half life of the radionuclide, but they eliminate ${ }^{131}$ I more quickly because of biologic elimination [14]. The available excretory pathways for radionuclide administered in therapy include urine, faeces, saliva, sweat, lachrymal fluid and breast milk. Each pathway has different safety issues and all can lead to contamination. The clearance rate from the patient's body can vary greatly for different pathways. In addition, they vary within any one pathway not only between radiopharmaceuticals but also for the same radiopharmaceutical in different patients [4]. Other factors affecting the activity levels in thyroid cancer patients were the amount of remnants tissue, renal insufficiency and patients abiding the rules such as cleaning urine contamination, changing clothes frequently, taking shower often and being well hydrated [11]. 
Upon administration of the dose, the labelled compound was readily absorbed from the gastrointestinal tract and distributed in the extracellular fluid of the body, concentrating in remnant thyroid tissue, the stomach, and salivary glands, with a portion recirculated back to these tissues. For most patients, some $30 \%-75 \%$ of the administered dose can be expected to be excreted in the urine, perspiration and saliva within the first 24 hours after ${ }^{131} \mathrm{I}$ administration [5, 15]. The removable ${ }^{131} \mathrm{I}$ activities from skin surfaces and room surfaces during the first 4 hours for all treatment doses were reasonably high. At this time, the patients did not take shower and there were a contact between each surface with patients hand and saliva. After the 10 hours, it showed some reduction in amount of activity levels for skin and room surfaces. This may due to the patients have followed the instruction given by medical staff, such as to wash hand and shower frequently, drink fluid liberally to allow the ${ }^{131}$ I excretion, and flushes the toilet bowl twice after used.

Among the room surfaces, the toilet bowl surface showed the highest level of removable contamination for all time interval, 4, 10 and 24 hours. There were some patients who did not comply the instruction given by the staff. The patients also did not flush the toilet bowl more than once as instructed. The radiation still remains in the toilet bowl and did not get into the decay tank. The high contamination depends on the behaviour of the patients in using the bathroom and probably results from the wrong position practice during the urination [8]. The men were proposed to urinate by sitting on the toilet to prevent possible contamination around toilet area. It was important to instruct the patient carefully not to spill any urine and flush the toilet 2 or 3 times after use. Patients were advised to wash their hands thoroughly after any cleaning of contaminated items. The bathroom sink and tub must be rinsed after being used [15].

Most of the administered radioiodine not taken up by thyroid tissue is excreted by the urine in the 48 hours or so following administration. However, some is excreted by perspiration, sweat and saliva. For this reason, patients are considered as a potential source of radiation contamination, especially during the first 48 hours following administration. If nursing staff come into contact with the patient, bed linen, etc. while in the room, they must wear a gown and disposable gloves. Further, the patient's meals must be served on disposable plates and utensils [3]. Disposable items should be placed in a separate waste container for collection, measurement and appropriate disposal. Contaminated objects may need treatment to reduce radioactivity levels, or even storage for decay.

However, the removable ${ }^{131}$ I activities from skins and rooms surface were still high at the time of discharge. Therefore, the patients still have to follow the instruction given by staff even at home. Since the removable activity from the hands and other areas of the body were significantly high at time of discharge, the patients were advised to refrain from participating in cooking and food preparation for some time to avoid food contamination. In order to avoid contaminated disposable utensils going into normal trash, it was advisable and recommended to exclusively used personal plate, glassware and silverware which must be cleaned by the patient in a private bathroom sink and kept in the patient's room for a daily use for 1 week. A failure in following the instructions by the patient resulted in contamination incident in some local community [15].

The activity levels of saliva and exhaled breath of the patients have positive correlations with treatment dose. So, it was necessary to instruct the patients to avoid from open mouth kissing and sharing personal with other family members. Extra precautions are necessary for patients with cold or flu symptoms because frequent sneezing and nose blowing can spread the radiation exposure to others [8]. In order to prevent contamination to the community, patients should be instructed to limit the time spent in public access the first few days and avoid places such as theatre, sport arenas or stadium where the option of getting a seat farther away from others may not always be possible [15].

The radiation safety precautions must be discussed properly with both patient and the family members to minimize radiation exposure to the family and community. With the proper education and clear instructions, the radiation exposure and contamination can be minimized [15]. The patients must be given clear instructions, including written instructions, on how to maintain doses to other individuals as low as reasonably achievable after they were released [12].

\section{CONCLUSION}

Radioiodine ablation is one of the most effective methods of treating the remnant thyroid tissue. High activity of ${ }^{131} \mathrm{I}$ is used to ablate thyroid remnant or to treat metastasis disease in patient with thyroid cancer. After the ${ }^{131} \mathrm{I}$ administration, the patient becomes a potential radiation hazard to other individuals.

The levels of removable ${ }^{131}$ I activity for thyroid cancer patients are reasonably high for skin and room surfaces during their hospitalization. Upon discharge, the removable ${ }^{131} \mathrm{I}$ activity for wipe samples is still significantly high for all the patients for various treatment doses. The study has shown that no significant correlation between treatment dose and level of surface contamination. These findings emphasize the importance of awareness on radiation surface contamination among hospital personnel and patients. It is important to instruct the patient to follow the radiation safety precaution in order to minimize radiation exposure and contamination hazards to personnel, family and community. It is recommended that the association of these factors is investigated in future studies. 


\section{Acknowledgements}

The authors thank Director, University Science Malaysia Hospital and Head of Nuclear Medicine

Department and their staffs for their permission and guidance in helping us carried out this study.

\section{REFERENCES}

[1] Hay ID, McDougall IR, Sisson JC. Perspective: The Case Against Radioiodine Remnant Ablation in Patients with WellDifferentiated Thyroid Carcinoma. J Nucl Med, 49, 2008,1395-1397.

[2] Meier DA, Brill DR, Becker DV, Clarke SE, Silberstein EB, Royal HD, et al. Procedure guideline for therapy of thyroid disease with 131 Iodine. J Nucl Med, 43, 2002, 856-861.

[3] International Atomic Energy Agency, Nuclear medicine in thyroid cancer management: a practical approach, IAEA-TECDOC1608, March 2009.

[4] International Atomic Energy Agency, Release of patients after radionuclide therapy, Safety Reports Series No.63, 2009.

[5] Thompson MA. Radiation safety precautions in the management of the hospitalized 131I therapy patient. J Nucl Med Technol, 29, 2001, 61-66.

[6] Barrington SF, Kettle AG, O'Doherty MJ, Wells CP, Somer EJ, Coakley AJ. Radiation dose rates from patients receiving iodine131 therapy for carcinoma of the thyroid. Eur J Nucl Med, 23, 1996, 123-130.

[7] Abu-Khaled YS, Sandouqa AS, Haddadin IM. Radiation exposure from radioactive iodine 131I in and surrounding the patient's room. Radiat Prot Dosimetry, 135, 2009, 64-68.

[8] Ibis E, Wilson CR, Collier BD, Akansel G, Isitman AT, Yoss RG. Iodine-131 contamination from thyroid cancer patients. $J$ Nucl Med, 33, 1992, 2110-2115.

[9] de Klerk JM. 131I Therapy: Inpatient or Outpatient? J Nucl Med, 41, 2000, 1876-1878.

[10] International Atomic Energy Agency, International basic safety standards for protection against ionizing radiation and for the safety of radiation sources, Safety Reports Series No.115, 1996.

[11] Mulazimoglu M, Edis N, Tamam MO, Uyanik E, Ozpacaci T. The evaluation of the external dose measurement of the patients treated with radioiodine therapy. Radiat Prot Dosimetry, 141, 2010, 233-8.

[12] U.S. Nuclear Regulatory Commission, Release of patients administered radioactive materials, Regulatory Guide 8.39, April 1997.

[13] U.S. Nuclear Regulatory Commission, Radiation safety surveys at medical institutions, Regulatory Guide 8.23, January 1981.

[14] Rutar FJ, Augustine SC, Colcher D, Siegel JA, Jacobson DA, Tempero MA, et al. Outpatient Treatment with 131I-Anti-B1 Antibody: Radiation Exposure to Family Members. J Nucl Med, 42, 2001, 907-915.

[15] Parthasarathy KL, Crawford ES. Treatment of thyroid carcinoma: emphasis on high-dose 131I outpatient therapy. J Nucl Med Technol, 30, 2002, 165-171. 